\title{
15
}

\section{Finance and Incentives to Support the Development of National Pharmaceutical Industries}

\author{
Alastair West and Geoffrey Banda
}

\section{Introduction}

There is a now a growing international consensus that development of the pharmaceutical industry in Africa can contribute to both economic development and improved public health. This final chapter begins by identifying the striking convergence of thought and initiative that has recently been generated across continental African representative bodies, international agencies and national governments. We outline this emergent consensus and then examine challenges it faces by focusing on the core interconnected policy issues of financing and incentives for industrial development in pharmaceuticals. A sustainable and expanding pharmaceutical industry must reach essential quality standards and also constantly upgrade, moving up the technology ladder while improving cost efficiency. This requires a cocktail of incentives in which finance is key (Chataway et al., 2009). These incentives, in turn, rely on the building up of appropriate financial capabilities within firms and financial institutions as well as within governments. This chapter innovatively traces the interconnections between micro-level financial capabilities and national government policy competences in the design and effective implementation of financial incentives and associated policies to facilitate industrial development in pharmaceuticals in Africa.

\section{The emerging commitment: transforming pharmaceutical manufacturing in Africa}

At the African continental level, the African Union Commission (AUC) identified the imperative of pharmaceutical industry development in 
their Pharmaceutical Manufacturing Plan for Africa (PMPA) (AU, 2007), endorsed at the African Union Heads of State and Government Summit in 2007. Progress on realizing the ambition espoused in this document was initially slow to materialize, prompting the Conference of African Ministers of Health (CAMH) to call at their fifth meeting in 2011 for a 'Business Plan' for the accelerated implementation of the PMPA. A partnership was formed later that year between the AUC and the United Nations Industrial Development Organization (UNIDO) to develop the business plan, and in May 2012 the resulting document (AU, 2012a) was approved by a special session of the CAMH in Geneva. In July 2012 the Business Plan was endorsed by AU Heads of State and Government at their summit in Addis Ababa.

Regionally and institutionally, collaborative work on local pharmaceutical development has snowballed. The African Ministers of Industry have also now recognized the pharmaceutical industry as a priority, in the Accelerated Industrial Development of Africa (AIDA) framework endorsed at their 19th meeting in Algiers in 2011. African Regional Economic Communities have also developed plans. The East African Community Regional Pharmaceutical Manufacturing Plan of Action 2012-16 was launched in 2011 (EACRPMPA, 2011). The West African Health Organization (WAHO) has been developing the Economic Community of West African States (ECOWAS) Regional Pharmaceutical Plan (ERPP) and its implementation. The ERPP explicitly aligns with the principles and objectives of the Business Plan for the PMPA, and WAHO has rapidly developed a comprehensive approach, despite wrestling with the unprecedented crisis of the Ebola outbreak in the region.

\section{The public health commitment}

International organizations concerned with public health are also now indicating growing support for this agenda. The Joint United Nations Programme on HIV/AIDS (UNAIDS) under the leadership of Michel Sidibé has long been an advocate of the importance of strengthening local production, in particular to address the sustainability of HIV/AIDS treatment, as well as access to medicines for tuberculosis and malaria. It is a central component of Pillar Two of the African Union's Shared Responsibility and Global Solidarity Roadmap for HIV, TB and Malaria Response in Africa, developed with support from UNAIDS (AU, 2012b).

In 2008 the World Health Assembly adopted the Global Plan of Action and Strategy on Public Health, a broad document that identifies the role that local production of essential medicines could play in improving public health. As part of its implementation, the World Health Organization 
(WHO) has run an EU Commission-funded project to assess this role. Phase 1 of the study concludes that the development of the local pharmaceutical industry does not inevitably lead to improved public health, and hence that promoting the public health impact should be central to efforts to strengthen the industry. These initiatives have helped to ensure that public health considerations are central to the Business Plans that are being developed. They plot a practical path whereby the industry can contribute to both public health and economic development agendas that were previously considered by some to be mutually exclusive (Kaplan and Laing, 2005).

The strong current consensus amongst the international community, that the development of the pharmaceutical sector in Africa is an imperative, was notably underlined by the Joint WHO Bulletin Editorial by Mr Sidibé, Mr Li (Director General of UNIDO) and Dr Chan (Director General of WHO) (Sidibé et al., 2014). The authors strongly supported the development of the industry in Africa through the implementation of the PMPA Business Plan.

\section{The challenge of implementation}

Practical bilateral and multilateral support for the industry is growing. The German government has a long track record of supporting the pharmaceutical industry in Africa. Since 2006 it has funded a UNIDO project on strengthening the local production of essential medicines in developing and least-developed countries, a project initiated by the previous UNIDO Director General Dr Kandeh Yumkella. Bilaterally through its aid agency Deutsche Gesellschaft für Internationale Zusammenarbeit (GIZ), Germany has supported the EAC pharmaceutical plan and many other initiatives such the bioequivalence centre in Addis Ababa (see Chapter 5) and initial feasibility studies for a similar centre in Ghana.

Other international support includes the United States Pharmacopeial Convention (USP) which, with funding from the United States Agency for International Development (USAID), has been running a programme on Promoting the Quality of Medicines (PQM), including capacity building for manufacturers and regulators. In 2013 it opened the Centre for Advanced Pharmaceutical Training (CePAT) in Ghana, to train regulators and the industry in quality assurance and quality control. The St. Lukes Foundation in Tanzania has similarly been training industry professionals on international standards of production through its Industrial Pharmacy Advanced Training Programme, taught by US academics from Purdue and Howard universities, supported by UNIDO. 
The need to exploit opportunities under the exemptions and flexibilities offered by the Trade Related Aspects of Intellectual Property Rights (TRIPS) agreement ${ }^{1}$ has led the United Nations Development Programme (UNDP), the United Nations Conference on Trade and Development (UNCTAD) and the African Regional Intellectual Property Organization (ARIPO), amongst others, to establish relevant programmes.

The PMPA Business Plan identifies the problem of a piecemeal approach that has not delivered rapid development of the industry, and proposes that coordination across different initiatives is required. The international organizations need to invest in supporting emerging national and regional processes to enable development of the industry. Coordinated technical assistance is required to support relatively weak skills availability in the short term and to engage in capacity development across public and private sectors for the long-term sustainability of the industry. National governments too need to invest to support their industries: this point was underscored during a high-level side event at the Ministers of Finance and Economic Planning meeting co-hosted by the African Union Commission and the United Nations Economic Commission for Africa (UNECA) in Abuja in March 2014.

Ghana is an example of a country where a coordinated agenda is progressing. In October 2013 early implementation of the AUC's PMPA Business Plan began in Ghana, following an invitation from President Mahama to the Chairperson of the AUC, Dr Nkosazana Dlamini Zuma. A technical assistance work plan was agreed by the national stakeholders and a consortium of partners including UNIDO, WHO, UNAIDS, UNDP, UNFPA, the New Partnership for Africa's Development (NEPAD), the African Network for Drug and Diagnostic Innovation (ANDI) and the Federation of African Pharmaceutical Manufacturer's Associations (FAPMA). The work plan recognizes both the critical need to build capacity within public sector institutions and the private sector and the need within the industry for time and support to invest in upgrading.

The need for complex cross-institution coordination to implement the work plan is illustrated by the collaboration with the Ghanaian Food and Drug Authority (FDA) to develop and implement a good manufacturing practices (GMP) road map; the development of training modules for industry on developing capital investment plans and managing capital project life cycles; the creation of a business linkages platform to enable companies to access the know-how that they require in the short term whilst internal technical capacity is developed; and a market data initiative to provide market transparency to inform policy makers, industry and investors in their decision making. Technical assistance has also 
been provided to assist government in assessing investment proposals made by pharmaceutical companies under the Export Development and Agriculture Investment Fund (EDAIF) stimulus package, described below.

\section{Upgrading, market consolidation and the challenge of finance}

Central to all this work is the recognition that the pharmaceutical sector in Africa needs to upgrade standards in order to be able to provide safe, efficacious, quality-assured essential medicines. Achieving this objective is a highly complex undertaking requiring coordinated action of many parties at national, regional, continental and international levels (Chapter 12). Africa-based companies are able to compete at international standards, contrary to some earlier expressed views (see Chapter 6; Chaudhuri and West, 2014). The most technically advanced companies such as Universal in Kenya (WHO-prequalified for its Lamivudine Zidovudine FDC), Quality Chemicals International Limited in Uganda (with additional site licence for Cipla's pre-qualified products) and four companies in Nigeria that have recently received WHO-GMP certification (including May and Baker and Evans Pharmaceuticals) have attained high international standards.

However, the industry's contribution to economic development and improved public health requires a broader swathe of companies to upgrade to international quality standards, not just for products to treat the major pandemics but for all medicines that have a critical role to play in treating communicable and non-communicable diseases. As earlier chapters have shown, companies across Africa are striving to upgrade their facilities and their manufacturing processes and procedures. However, whilst there have been no published systematic studies on the range of quality standards to which manufacturers on the continent adhere, it is clear that many companies licensed to manufacture pharmaceuticals in Africa currently operate in premises and/or have quality management systems that fall below what should be acceptable.

The concept of the GMP 'road map' establishes rising quality targets over a defined period of time. During transition to meet these milestones, those companies that are operating below them should be restricted to manufacturing products where the risk to health is minimized. Such a stepwise approach creates a transition process for the industry whilst protecting public health. So long as the requirements are enforced by credible sanctions, the framework can discourage unproductive use of 
subsidies by manufacturers not in practice investing in upgrading. It also provides some market protection for leading companies that have made significant investment, since they can sell a broader range of products during the transition phase.

The PMPA Business Plan focuses initially on generic small-molecule non-sterile production of final formulations in Africa. Even with this subset of essential medicines, the complexity of the system within which manufacturing takes place is significant (see Chapter 2). The industry has multiple stakeholders, operates in widely varying contexts across countries and regions, and includes manufacturers at significantly different levels of industrial development.

Nevertheless, some general requirements for industry development can be identified, and of these the central requirement is finance. Companies need to access capital to invest in retrofitting facilities or building new plants to meet international standards. The magnitude of investment required will depend on many variables including the specific pharmaceutical forms that a manufacturer wishes to produce, the scale of the plant and the starting point of the organization, but most companies will require at least US $\$ 10$ million (see also Chapter 5 for the financial requirements for a start-up). The efficient use of this investment requires that companies in this knowledge-intensive industry can access the capabilities to design and build GMP-compliant plants and develop or acquire the capabilities to run them. Companies need assistance to access know-how, time to develop plans and implement them, and more time to develop the capabilities first to operate efficiently and then to adapt and innovate.

Upgrading is done by companies, not governments. But policy makers and international development organizations need to understand the challenges faced by manufacturers, and to work with them and with national and regional entities to enable effective upgrading whilst avoiding wasteful use of scarce resources. The AUC has recognized this need for close collaboration, convening a consortium of continental and international partners, including the Federation of African Pharmaceutical Manufacturers Associations (FAPMA), to implement the PMPA Business Plan. The consortium will work with African trade associations, regions and sovereign states on strategies for upgrading the industry.

\section{Regulatory market shaping}

In order to invest sustainably, pharmaceutical companies also need access to a large and effectively regulated market in which returns can be 
made. Further strengthening of regulatory authorities is needed to ensure that legitimate manufacturers do not face competition from spurious, substandard and counterfeit products. Pharmaceutical manufacturers also need to utilize capacity efficiently in order to be competitive, and market scale is an important contributor to achieving cost efficiency. Since many African countries' populations are relatively small, current efforts to defragment African regional markets, and confidence in their likely success, are vital prerequisites to mobilizing investment for many pharmaceutical manufacturers. While for a few firms international donor-funded markets may offer larger-scale market opportunities, the sustainability of an exclusive focus on these markets in the long term is questionable.

Important progress has been made in the direction of regional market consolidation, through the African Medicines Regulatory Harmonization initiative (AMRH), particularly in the EAC and ECOWAS Regional Economic Communities. The documentation for regulatory approval across member states will at least be standardized, removing significant transaction costs from manufacturers, and boding well for increasingly harmonized regulatory requirements in the future (see Chapter 12).

Finally, as earlier chapters have documented, local manufacturers are frequently at an inherent disadvantage in competition with imported medicines, and corrections to the tax and tariff frameworks are required at regional level. The ECOWAS Regional Pharmaceutical Plan (ERPP) advocates for zero tariffs on raw materials, machinery and equipment for pharmaceutical manufacturing within the Regional Economic Community and exemption of inputs from VAT. It also recognizes the need for an appropriate regional framework to support the stepwise approach to upgrading.

Such initiatives can help investors to assess potential returns. However, the quantification of the market opportunities remains elusive, given the paucity of market data for most African countries and regions. This market opacity increases the perceived risk for investors, leading in turn to higher interest payments through an increased risk coupon required for debt providers, or to a higher internal rate of return required by equity investors. The cost of investment capital for African pharmaceutical investors remains a barrier for many companies in countries where interest rates on bank loans may exceed $25 \%$. The next two sections tackle the funding challenge in more detail, first from the point of view of the manufacturers and private financing institutions, and then from the point of view of governments seeking to enable investment for industrial growth. 


\section{Building financial capabilities in manufacturers and financial institutions}

The African local pharmaceutical industry is playing technological catch-up based on building technological capabilities (Chapter 2). These technological capabilities are sometimes summarized as knowwhat, know-how, know-why and know-who (Ernst and Lundvall, 1997). They include the skills needed for investment, production and creating market and non-market linkages (Lall, 1992): using technology effectively for expansion; handling key production systems from quality control and operation and maintenance to adaptation and improvement; and dealing effectively with suppliers and customers. While it is accepted that finance plays a strategic role in funding working capital requirements and capital investment, it is however less well documented that many Africa-based firms lack essential capabilities in raising and managing finance effectively (Banda, 2013).

The essential finance capabilities include the ability to understand a project life cycle and phase finance and to structure the most relevant type of financial product. It also encompasses lending technology, pricing and an overall financial approach that does not choke the financial health of the borrowing firm, but rather enhances its productive capacity. Financial capability involves knowing where to get the most appropriately structured financial products, from whom, and when to use them. These firm-level financial capabilities are particularly important for developing-country contexts, where financial systems are not well developed and growth of capital-intensive enterprises depends on capital investment financing (long-term foreign loans), in most cases from offshore sources.

In this section we explore finance capability in the firm and financial institution. This discussion is grounded in empirical work carried out on Zimbabwean pharmaceutical companies and financial institutions, and additional interviews with pharmaceutical sector players in Uganda, Kenya, Tanzania and Ethiopia up to 2013. We analyse how firms use finance expertise and competencies, to identify and manage short-, medium- and long-term funding cycles. We focus on financial institutions at a micro-level and attempt to tease out the technical knowledge and capabilities needed to competently assess, classify, monitor and manage risks. The classes of risk may include credit, management, performance, regulatory, foreign exchange, payment and market risk which in various combinations manifest during a project lifecycle. 


\section{The financing context for pharmaceutical firms in Africa}

Economic, social and financial history shows sources of finance for setting up enterprises globally have been predominantly internal or own finance, made up of savings, wealth and loans from family and friends (Lazonick and O'Sullivan, 1997a, 1997b), in the industrialization era. Enterprise growth was funded internally by retained earnings, and externally banks were the most prevalent source of finance historically (Lazonick and O'Sullivan, 1997a, 1997b), specifically for the period from 1970 to 1989 (Corbett and Jenkinson, 1996). Other sources of external finance were venture capitalists and capital markets. The key determinants of financing source were the enterprise's management experience, skills and credit reputation.

Growing companies with experienced management, poor to good future prospects, medium to high risk and established credit reputations are likely to use banks as sources of external funds (Corbett and Jenkinson, 1996). African enterprise financing studies similarly find that of all external funding sources, bank finance has been the most prevalent (Fafchamps et al., 1995.)

For established companies, with established credit records, low credit risk and run by experienced management, capital markets are the most likely source of external finance. However, capital markets did not play a major role in raising capital for industrialization, except to a certain extent in the US (Lazonick and O'Sullivan, 1997a, 1997b). Capital markets were used particularly to transfer ownership of corporate entities from family-run or close-knit ownership structures to publicly quoted companies, rather than to raise finance for industrialization.

Capital markets, however, are of little significance in Sub-Saharan African markets because of their small scale and low capitalization, with the possible exceptions of South Africa, Nigeria and Kenya. Venture capital and capital markets are more the exception than the norm in Africa. A more important source of external finance is foreign direct investment (FDI), which can embody technology flows (Portelli and Narula, 2004). FDI allows the developing country to import technology without payment, since the investor brings in knowledge and skills required to operate the technology. Ensuring effective technology transfer is a challenge. However, data on financing manufacturing industry in seven countries in Sub-Saharan Africa indicate that FDI and external/offshore financing were the main sources of capital, reinforcing Ndlela's (2007) and Riddell's (1990) accounts of FDI as being critical for the emergence of the manufacturing industry in countries such as Zimbabwe. 
How then do firms select internal or external avenues for financing investment? Internal funds include retained earnings, depreciation or fresh equity injection from existing shareholders. External funds include bank debt, hybrid bonds or issuing of new equity to new shareholders. When internal funds are limited, management seeks external funds. A 'pecking order' theory (Myers, 1984) argues that in the face of limited information, firms will prefer to use own financial resources such as retained earnings or profits; only if self-financing is insufficient will management use external debt instruments: first bank debt, then hybrid bonds, and the last option will be new equity. The order of preference is determined by the objective of retaining management control. Hybrid securities such as convertible bonds dilute management control less, and carry fewer external accountability (discipline and reporting) requirements compared to stock exchange equity. Equity is a last resort because of onerous reporting standards and controls when dealing with broad shareholding structures and professional managers as agents of shareholders (Myers and Majluf, 1984).

\section{Finance capability gaps in pharmaceutical firms}

Faced with these financing constraints and choices, a firm with limited internal funds needs to develop capabilities to scan for potential funders and financial products nationally, regionally and internationally. The firm needs to articulate its organizational, dynamic and technological capabilities in a robust well-argued project finance document with supporting data. In building the project finance document and data, the firm needs to use its external networks to assess economic, industry and business environments and attendant risks, as well as stress-testing project data. The finance department as the key operating contact point with external financiers articulates the firm's competencies and capabilities in procurement (trade credit included), research and development, production and engineering, as well as sales and marketing capabilities. Table 15.1 Column 1 summarizes the financial capabilities the firms require.

The firm then needs to negotiate with financial institutions on appropriate finance products by competently structuring the debt or equity relevant to business needs. If this is not managed properly, financial institutions can push their preferred high-yielding products. The firm may then be burdened with finance products characterized by high charges, onerous covenants, triggers and security (collateral) requirements. Firms thus have a great deal to gain from finance capability to identify and structure appropriate borrowing products and negotiate on pricing. 
Table 15.1 Finance capabilities at the firm and financial institution levels

\section{Pharmaceutical firms' required competencies}

Identify the businesses' financial needs: Working capital and capital investment requirements

Ascertain the best available financing structure; a mix of short, medium and long term finance through debt, equity or hybrid instruments to structure the funding model for the firm

Structuring the funding model requires development of knowledge of lending technologies and funding instruments on the market and outside national borders

Crafting a competent project finance proposal that identifies project risks and how they are managed through the management, organisational and technological capabilities of the firm.

Competency to apply financial resources to originally identified funding needs, and through financial management capability run successive asset conversion cycles to generate profit and maintain commercial viability.

Competence to repay interest and principal on time, and meet challenges in restructuring debt after negotiation with the funders.

\section{Funder's (financial institutions') required competencies}

Understand the industry, business, economic, political, and regulatory environment.

Sector-specific knowledge to competently identify, analyse and manage risks in business, industry, management, markets and regulation. Some funders have a central set of industry and sector specific skills that assists all business units.

Alignment of internal capabilities in prospecting, screening, analysis, structuring financial products/ funding schemes, document perfection, disbursement of funds, monitoring and control and eventual repayment of principal and interest.

Whilst managing projects identify opportunities and the exhibit flexibility to change within and after the life of the funded project.

Through learning-by-doing transfer skills and capabilities developed to other industrial sectors and within departments in the institution.

Source: Compiled by author from fieldwork in Zimbabwe, 2010-13.

Our interview data show, however, that these finance capabilities are lacking in many firms. One respondent in Zimbabwe remarked that the firms 'were afraid to approach international banks because they are not able to produce a robust project proposal and are afraid of being asked questions'. Crafting a project proposal requires knowledge of the firms' 
capabilities, what the money is needed for, and how revenue will be generated to repay debt. Based on the dynamics of the proposed project business cycles, the firm needs to be able to know which financing tool would be most advantageous to it instead of waiting for the bank to always propose the mode of financing.

\section{Building finance capabilities in banks}

Finance capability in financial institutions refers to their ability to source projects to invest in (investment capability); analyse the risks; structure the finance instrument, price the debt instrument and loan duration; followed by monitoring and control and eventually repayment of the debt by the borrower. Various players within the financial institution interact in the process of financing a project. The internal staff identify and analyse risks that include but are not limited to business, industry, management, country, political and foreign currency risks. The risk management process is closely tied to loan structuring, documentation, disbursement and monitoring and control procedures.

These processes depend on in-depth knowledge of the sector being assessed (Table 15.1). In practice, information is opaque and hard to assess. Our research evidence from Zimbabwe and secondary data evidence from East and West Africa suggests lack of in-depth and relevant pharmaceutical sector knowledge by financial institutions. A repeated claim by pharmaceutical executives is that financial institutions do not understand the business of African pharmaceutical drug manufacture. Evidence from Zimbabwe suggests that financiers also need to develop an in-depth knowledge of the economy, industry and health sector for preliminary analysis of projects. They need to greatly improve their networking within the financial sector and the national economy to acquire relevant information for prospecting and analysing projects.

Table 15.2 maps, using Lall's (1992) concept of firm-level technologies, the capabilities needed by these financial institutions. The table maps prospecting, risk analysis, facility structuring and documentation, loan approval, loan disbursement, monitoring and control and ultimately loan repayment. Under prospecting capabilities, relationship managers use investment and networking capabilities to scout different industrial sectors for potential deals. They need intimate knowledge of the economy, industry, various business sectors, credit policy and underwriting standards. Interview respondents pointed to the use of both codified and tacit knowledge at this early stage. They emphasized the importance of experienced 'old-timers' for connections and 


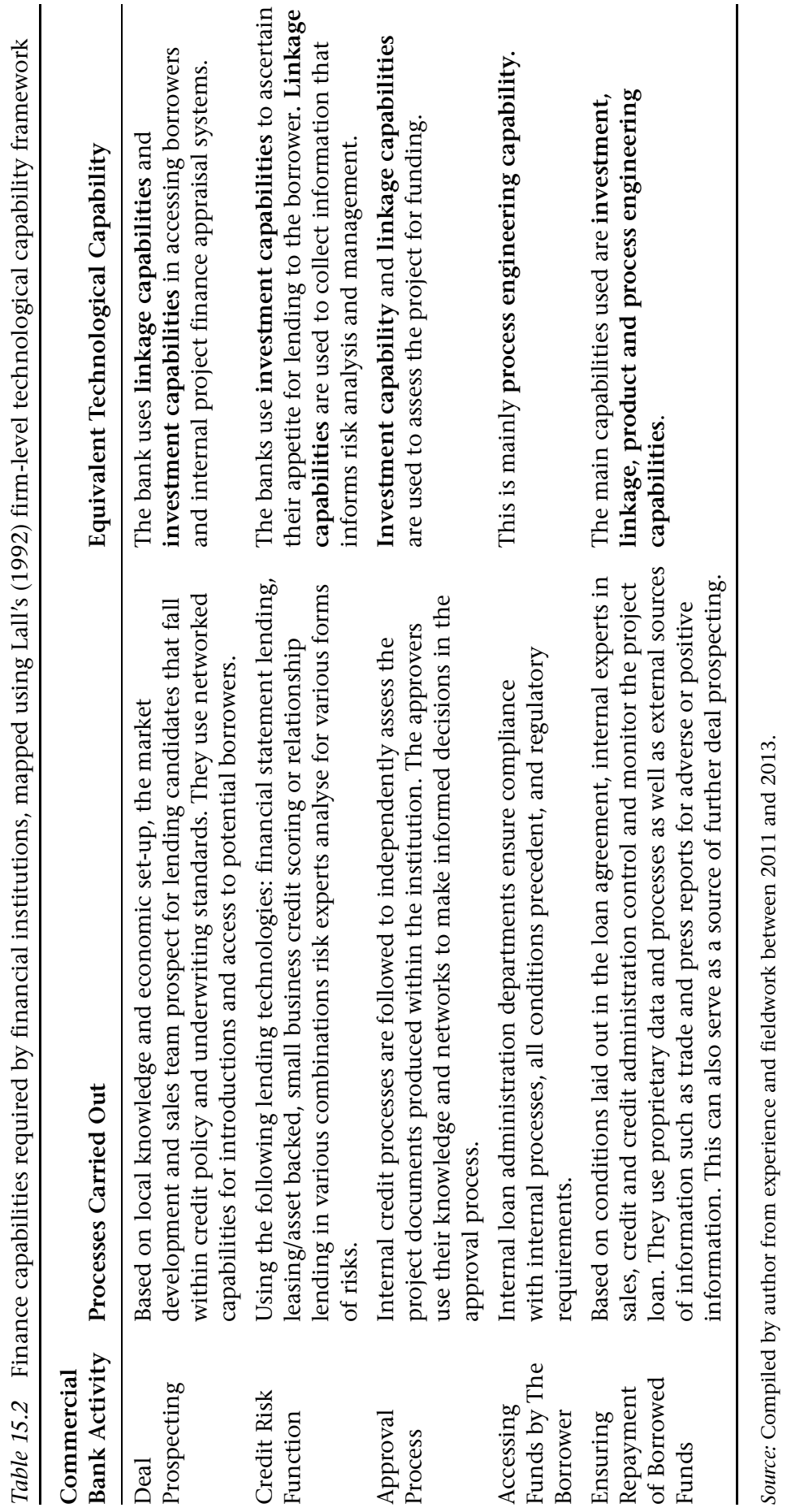


networks evidencing the need for linkage capabilities. Risk analysis, loan structuring and approval use codified and tacit knowledge for decision making by way of agreed financial ratios and internal metrics. Chief Risk Officers also acknowledged the inherent use of 'gut feel', implying relevance of tacit knowledge.

Capabilities that need to be built thus include loan disbursement, monitoring and control and finally repayment of the loan (Table 15.2). The process involves agreement of terms and conditions between the borrower and financier through a loan agreement document (commonly called the loan facility). On fulfilment of the conditions precedent, the loan administration department processes the security for the loan facility and disburses the funds. Monitoring and control is based on the conditions set out in the loan facility. The capabilities at this stage include those of product and process engineering and also linkage capabilities. Our evidence from empirical work in Zimbabwe and interviews with pharmaceutical executives from East Africa shows a clear perception of financial institutions' deficit of in-depth knowledge of pharmaceutical manufacturing business dynamics and attendant risks and opportunities. These challenges were acknowledged by financial institution executives who agreed that they did not understand the pharmaceutical industry. This information asymmetry and opacity leads to classification of the African pharmaceutical manufacturing sector as high-risk, negatively influencing loan pricing.

The financiers and pharmaceutical executives interviewed proposed to tackle these failings through training and exposure to the pharmaceutical industry. Finance capability cannot be taken for granted and requires purposive and strategic investment to build these competences. An illustration of what can be done is drawn from an innovative midcareer recruitment programme of one international bank in Zimbabwe; Standard Chartered Bank. This programme allowed the bank to build skills and a broader knowledge base by recruiting non-traditional bank trained professionals (Table 15.3). This formed part of an Africa-wide initiative by Standard Chartered Bank Africa.

A senior manager who has since left the bank said this programme was a short-term strategic move to fill an identified skills gap. This seems paradoxical; an innovative and strategic approach which could have contributed a longer term strategy to generate risk analysis skills for project management and build capabilities was relegated to a short term measure. The senior manager argued that once the identified skills gap had been filled, they could revert to the usual graduate trainee programme and train in-house. He argued that the mid-career entrants 
Table 15.3 Recruitment of non-traditional banking skills to build finance capability by one Zimbabwean international bank in 1998-2000

\begin{tabular}{lll}
\hline Intake & Skills Sets & Roles in the Bank \\
\hline 1 & Engineers, Economists & $\begin{array}{l}\text { Credit Risk Analysis, Monitoring } \\
\text { and Management; Relationship } \\
\text { Management; Processing; Global } \\
\text { Markets; Retail Banking }\end{array}$ \\
& & Credit Risk Analysis, Monitoring \\
2 & Engineers (electrical, & and Management; Relationship \\
& mechanical and civil), & Management; Processing; Marketing; \\
& Scientist, Agriculture and & Treasury (Global Markets); Retail \\
& Geo-Sensing, Computing & Banking; Direct Banking; Branch \\
& Technology and & Management; Credit Operations; \\
& Programming, & Interest Recalculation; Structured \\
& & Trade Finance; Transactional Banking; \\
& Syndicated Lending \\
& Credit Risk Analysis, Monitoring and \\
& & Management; Finance; Treasury Back \\
& & Office Operations \\
\hline
\end{tabular}

Source: Compiled by author from fieldwork in Zimbabwe (2010-13) and experience.

came in at middle-management level, were more expensive to the bank and so reverting to the cheaper junior level graduate trainees helped contain costs. However it is clear that these 'non-traditional bankers' had added value to credit risk analysis, management and monitoring, with their specialist skills and in-depth technical knowledge. They served as a knowledge bank that junior and senior management tapped into to understand once-opaque industrial operations. As Table 15.3 shows, many of these recruits' skills were used to build a deeper technical knowledge of industries that the bank funded. The short lived innovative programme (a flash of strategic brilliance) demonstrates the lost opportunity for long term skills and finance capability building.

\section{Government interventions to assist companies to access investment capital}

There is therefore a need for micro-level financial skills to be developed within the industry and within the financial community. However, it is also recognized that governments need to intervene to enable companies to access affordable investment capital. What types of interventions can governments employ to help resolve this critical issue? A government can provide soft loans, or it can use direct intervention to reduce 
the cost of financing (e.g. interest subsidies). As well as such specific initiatives, it can intervene to create a conducive industry context that makes investment in the sector attractive to various providers of capital, thereby reducing perception of risk and theoretically increasing the availability of and reducing the cost of capital. Finally, a government can employ time-limited incentives to support industry investment.

\section{Direct capital provision}

Many industry actors and a number of trade associations have called for their governments to set up designated funds for low-cost investment in the pharmaceutical sector. One example is in Ghana, where in 2014 the President announced that Cedis 50 million would be set aside from the Export Development and Agriculture Investment Fund (EDAIF) for soft loans to the pharmaceutical sector (with recent currency depreciation this is now equivalent to less than USD $\$ 20$ million). The government of Nigeria proposed a Naira 200 billion (roughly USD \$100 million) fund to support the sector, but this has yet to materialize.

These limited examples to date suggest that for most countries, direct capital provision may not be viable or of sufficient impact to enable the transformation of the industry. Where countries (such as Ghana) have more than a handful of manufacturers, it is unlikely that governments have resources to create a fund of sufficient magnitude to tackle the capital funding gap for a meaningful number of companies. Furthermore, a government making direct capital provision must be equipped to make informed decisions, to ensure these scarce public resources are not wasted through poor investment. Public funding of investment capital for the pharmaceutical sector therefore demands the development of financial capabilities of the type just outlined within governments as well as private institutions.

However, where limited resources can be brought to bear, there is the potential for leveraging these public funds to assist a number of companies to achieve an affordable cost of capital. For example the proportion of individual investments that a fund supports could be limited to a certain percentage of capital required. A blended cost of capital combining public with commercial investment can be more affordable than pure commercial capital. Such leverage could be enhanced if governments consider taking a junior debt position, thereby perhaps reducing the risk coupon required by private sector investors.

Assuming that an investment fund can be regularly recapitalized, through a sustainable funding mechanism such as a levy on pharmaceutical imports for example, public resources could be allocated in tranches. In this way the capital requirements of an organization at one 
particular time during a project lifecycle can be addressed without tying up resources required for total overall capital requirements, and therefore a greater number of companies can be supported simultaneously over a number of years.

\section{Direct government expenditure to reduce the cost of financing}

Governments can also facilitate access to affordable investment capital through subsidizing interest payments. Interest subsidies were made available to Indian pharmaceutical manufacturers to support their development. Using public resources to support the servicing of debt rather than providing the capital itself can be a more efficient use of public resources. However, limitations on the political acceptability of direct transfer of public funds to the private sector, given other pressing demands on public expenditure, may make such a model untenable for many countries. At the least, mechanisms are essential to control waste of resources and limit government financial liabilities.

Can criteria be established for companies to be eligible for such subsidies? There is widespread anxiety about governments trying to 'pick winners', or rather failing to spot losers, thereby backing unsustainable manufacturers and losing scarce funds to unintended uses. All industrial policy interventions require the development of industrial skills and capabilities within government.

Another concern may be that an interest subsidy approach can reinforce a debt-financing model, shifting the industry away from equity financing. Equity financing should form an element of the capital structure of firm in which the return on investment is necessarily long term. Hence, parallel mechanisms may be needed to encourage companies to seek some equity financing to cover some of the capital requirements for upgrading. These mechanisms could include facilitating repatriation of profits, to stimulate interest from foreign investors, or levelling the playing field between debt and equity financing through limiting the tax shields that debt conveys.

Interest subsidies provide an investment incentive, but have the advantage that they do not have a direct impact on revenues and operating profitability, unlike preferential pricing or other forms of market protection. They may therefore be a constructive means of support in that they do not encourage uncompetitive practices.

\section{Creating an industry context that attracts capital}

Creating a conducive context for pharmaceutical manufacturing involves the combination of multiple interventions, not all of which 
are necessarily within the purview of individual governments. The importance of a regional market has already been highlighted. However, individual governments can tackle dimensions such as the overall business environment (corporate tax rates and special economic zones, for example), as well as sector-specific aspects such as strengthening regulatory oversight and developing human resources. While credible forward-looking statements from governments help, genuine impact does require observable developments and interventions.

\section{The role of time-limited incentives}

The PMPA Business Plan, regional plans and national strategies all call for time-limited incentives. Given the specific nature of the pharmaceutical industry, what is the purpose of these incentives, what are the tools available to governments and how do these vary by country context?

First, there is a clear distinction to be made between time-limited incentives and policies to induce structural change whether on the demand or supply side. For instance, resolving the widespread unequal tax and duty regimes applied to imports versus inputs for local production (Chapters 2-6) is a long-term structural approach that needs to be embedded. However, it is also possible to decide to adjust tax regimes for a limited period of time, to convey a temporary competitive advantage to local producers in competition with imports.

Examples of time-limited incentives that could be utilized can be drawn from the policy actions already implemented within Africa, on other continents, and for other industries. A major concern for manufacturers is funding their working capital requirements. For African companies this is a particularly profound problem, since they need to import the vast majority of inputs from abroad. Often, credit terms are used up before raw materials can even begin to be converted into final formulations. Such concerns can be addressed through provision of working capital credits, an approach that was used successfully in India, or through underwriting letters of credit enabling manufacturers to secure improved credit terms from their suppliers.

Other government incentives can focus on reducing the tax burden for which companies are liable, as a means to free up resources to fund investment. Effectively, this provides an additional margin that can make local products more competitive in the transition period, as companies learn to operate facilities more efficiently. Examples of incentives to achieve these intents are tax holidays and special depreciation provisions. The latter were once again used in India where companies 
were able to include depreciation over time on the profit and loss statements up to $150 \%$ of the capital cost for plants and equipment.

Previous chapters have covered the use of procurement preferences and restricted lists and highlighted the potential for such approaches to give a boost to local manufacturers. There are acknowledged downsides associated with market protection, particularly if done at a national rather than a regional level, since it can, for example, reduce competition. Introducing preferential import tariffs on inputs for local production is another mechanism to provide a degree of protection for nascent industries. Again, a regional approach that consolidates markets can help to implement this while sustaining local competition.

This discussion is far from exhaustive in covering the range of industrial policy incentives available. The relative merits of the different tools depend strongly on context, but their fundamental purpose is to support the industry during a transition phase so that companies can build capabilities, develop plans for upgrading facilities and execute them, whilst continuing to compete viably during the transition. This transition period also provides time for policy makers to put in place longer term initiatives to sustain the economic and technical viability of highquality manufacturing, including defragmenting markets and building the institutional capacities and skills within government and industry actors. Initiatives are under way to address these structural realities, but a much stronger push is still required, with the support of international technical assistance programmes to build government skills and accelerate industrial knowledge accumulation.

\section{The importance of country context}

Each country considering development of its pharmaceutical industry faces a unique context which determines what policies and initiatives are required and feasible. With a large domestic market, a government could employ protective measures to support industry growth, using import substitution as Ethiopia has done (Chapter 4). For smaller countries, however, regional exports are likely to be a critical part of the business mix for a sustainable industry. Botswana has an expressed desire to establish a pharmaceutical industry, but with a population of 2 million, its strategic positioning objective is to become a regional centre for pharmaceutical production.

Another key variable is the state of the public finances. All countries face choices as to where they invest public resources, and where such resources are severely constrained, the Ministry of Finance and the National Revenue Authority are likely to resist policy initiatives that will 
reduce the contribution of current taxes levied on the sector to government income, or that increase expenditure through for example procurement preferences or industry subsidies. For example, at present, Ghana and Kenya face difficult public finance situations, making budget-neutral support mechanism such as domestic market protection an attractive option. While the options open to governments and their relative power vary according to the specific context, complementary regional initiatives such as tariff harmonization, regulatory harmonization and general collaboration between countries can increase the leverage that national government interventions have to stimulate upgrading and development of the sector.

\section{Conclusion}

We began by highlighting recent developments at regional, continental and international levels that have generated a new convergence of highlevel political will to support the development of the pharmaceutical manufacturing industry in Africa. The chapter has sought to shift the understanding of the key challenge of investment finance within those strategies, from a focus on access to capital to a framework of collaborative financial capability building in firms, financial institutions and governments. The chapter outlines the shared political recognition of the need for time, protection and incentives to build the industrial base through upgrading and transition to higher skills and quality standards. Development of new skills within interconnected institutions, evolution of regional markets and firms making the requisite investments and learning to operate competitively at international standards cannot happen overnight. This final chapter, framed by the intensive international and regional collaborations that are now under way, also frames the detailed studies in this book as a timely contribution to those endeavours.

\section{Note}

1. See the World Trade Organisation website at https://www.wto.org/english/ tratop_e/trips_e/trips_e.htm for more information on TRIPS.

cC (i) Except where otherwise noted, this work is licensed under a Creative Commons Attribution 4.0 Unported License. To view a copy of this license, visit https://creativecommons.org/version4 